\title{
Sensor Monitoring Suhu Komputer Berbasis Port Paralel Dengan Menggunakan Rangkaian IC LM35 dan ADC 0804
}

\author{
Hadi Santoso \\ Program Studi Teknik Mesin, Fakultas Teknik, Universitas Borneo Tarakan, Jl.Amal Lama No.1, \\ hadisantoso.ubt@gmail.com / hadisantoso@borneo.ac.id \\ Ilmawan Suryapradana \\ Program Studi Teknik Mesin, Fakultas Teknik, Universitas Borneo Tarakan, Jl.Amal Lama No.1, \\ ilmawanpradana@borneo.ac.id / ilmawanjie@gmail.com
}

\begin{abstract}
Abstrak
Telah dibuat sensor suhu yang memanfaatkan IC LM35 dan ADC 0804 yang terkoneksi ke komputer yang dapat mendeteksi dan memonitoring tingkat suhu dari komputer tersebut. Monitoring dilakukan dengan memberi tiga tanda kondisi suhu komputer yakni Aman (suhu dibawah $50^{\circ} \mathrm{C}$ ), Siaga (suhu antara $60^{\circ} \mathrm{C}$ hingga $70^{\circ} \mathrm{C}$ ) dan Bahaya (diatas $75^{\circ} \mathrm{C}$ ). Ketiga kondisi dapat ditampilkan melalui layar komputer itu sendiri sehingga memudahkan dalam memonitoringnya. hasilnya sonsor monitoring dapat bekerja dengan baik sebagai. Hal ini sebagai salah satu cara perawatan komputer dari suhu overheat komputer yang dapat merusak komputer itu sendiri.
\end{abstract}

Kata Kunci: Sensor pendeteksi suhu laptop/PC, monitoring suhu, IC LM35, ADC 0804

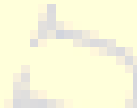

\section{Abstract}

Temperature sensors have been made that utilize IC LM35 and ADC 0804 which connected to a computer that able to detect and monitor the temperature level of the computer. Monitoring is carried out by giving three signs of computer temperature conditions which are: Safe (temperature below $50^{\circ} \mathrm{C}$ ), Caution (temperature between $60^{\circ} \mathrm{C}$ to $70^{\circ} \mathrm{C}$ ) and Danger (above $75^{\circ} \mathrm{C}$ ). All three conditions can be displayed through the computer screen so It's easier to monitor. As the result, monitoring sensor operates well. This is one way to maintain the computer from overheating that can damage the computer itself.

Keywords: Laptop / PC temperature detection sensor, temperature monitoring, IC LM35, ADC 0804

\section{PENDAHULUAN}

Saat ini komputer (PC) dan laptop bukanlah sesuatu yang langka. Komputer sangat dibutuhkan dikehidupan sehari-hari dengan berbagai bentuk dan berbagai kebutuhan. Karena pentingnya keberadaan laptop untuk tiap individu, maka penting pula untuk merawat laptop agar kondisinya tetep baik untuk digunakan. Sebagai peralatan elektronika yang memiliki komponenkomponen listrik yang ukurannya kecil, laptop sangat sensitif dan beresiko mengalami kerusakan karena berbagai faktor. Salah satu faktor yang dapat merusak laptop adalah pemakaian yang telalu lama hingga menyebabkan laptop panas dan menggangu kualitas kerja laptop.

Salah satu alat atau komponen di PC maupun laptop yang menyebabkan proses distribusi panas adalah prosesor CPU. Prosesor merupakan bagian utama computer personal unit (CPU) yang menentukan kinerja CPU secara keseluruhan. Agar kerja CPU efektif diperlukan penyerapan dan penyebaran panas yang baik. Jika CPU mengalami overheat dengan suhu maksimal 339 $\mathrm{K}, \mathrm{CPU}$ akan menjadi lambat untuk memproses kerjanya dan umur CPU akan lebih singkat bahkan bisa terjadi kerusakann [1]. Overheat pada prosesor CPU akan terjadi jika CPU digunakan secara berkelanjutan (terus-menerus) hingga temperatur CPU melebihi batas maksimum CPU. Panas dari CPU yang mempengaruhi panas keseleruhan komponen laptop/PC lainnya sehingga akan mempengaruhi kinerja laptop/PC [2].

Berdasarkan alasan diatas, maka penulis tertarik untuk merancang sensor monitoring suhu laptop yang memanfaatkan IC LM35 dan ADC 0804 yang didesain sedemikian rupa sehingga dapat mendeteksi suhu dari laptop yang digunakan sehingga dapat dijadikan sebagai monitoring dan salah satu langkah perawatan laptop / komputer. Sensor ini disusun sedemikian rupa sehingga dapat terhubung lansung dengan laptop melalui interface vga dan secara lansung menampilkan kondisi laptop serta tampilan temperaturnya. 


\section{METODE}

Dapat digambarkan bahwa sistem kerja atau alur kerja pembuatan sensor suhu ini adalah sebagai berikut [3] :

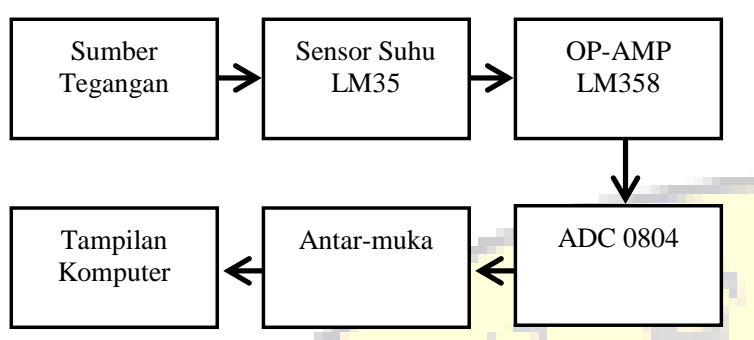

Gambar 1 : Alur sistem kerja

\section{Sumber Tegangan}

Sumber tegangan adalah usb dari laptop yang akan diukur suhunya. Usb dari laptop memberikan tegangan DC. Usb akan menyuplai tegangan sebesar 5 volt sebagai sumber tegangan seluruh sistem sensor.

\section{$\underline{\text { IC-LM35 }}$}

IC LM35 adalah IC yang dimanfaatkan sebagai sensor suhu. Kemampuan mengukur suhu IC LM35 adalah 550C sampai dengan 1500C. Output tegangan dari IC sensor suhu LM35 yang berkisar antar $0-1.5$ Volt dikuatkan 3.2 kali dengan IC op-amp LM358. Hasil penguatan dimasukkan ke IC analog to digital converter ADC 0804 sebagai input. Sesuai dengan lembar data, keluaran LM35 adalah $10 \mathrm{mV} /$ derajat celcius. Jadi setiap kenaikan 1 derajat celcius, akan bertambah $10 \mathrm{mV}$ [4].

\section{Op-Amp LM-358}

Output tegangan dari IC sensor suhu LM35 yang berkisar antar $0-1.5$ Volt dikuatkan 3.2 kali dengan IC op-amp LM358. Konfigurasi IC-LM35 memberikan tegangan sinyal masukan dari LM35 (Vin), diasup secara langsung ke terminal non-inverting $(+)$. Dengan demikian berarti bahwa perubahan tegangan keluaran Vout dari penguat memiliki polaritas "positif" terhadap tegangan masukannya, artinya tegangan keluaran tidak dibalik polaritasnya. Hasil tegangan keluarannya akan sefasa dengan tegangan masukannya. Berikut ini adalah gambar skematik pin keluaran dari IC op-amp LM358:

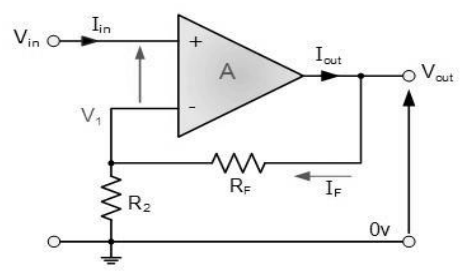

Gambar 2. Konfigurasi Penguat Tak Membalik (Non-Inverting Amplifier) yang diterapkan pada IC LM358

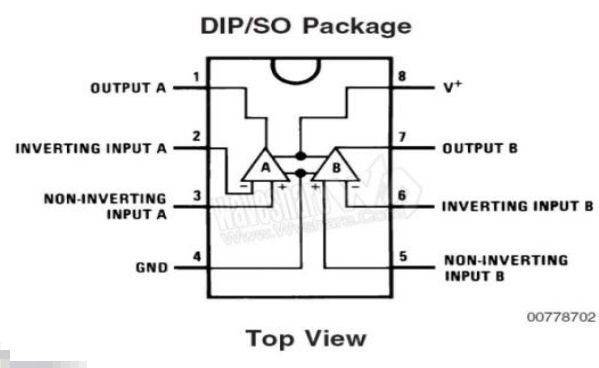

Pin 1 dihubungkan dengan input ADC 0804. Pin 2 dihubungkan dengan RF dan RI. Pin 3 dihubungkan dengan output dari IC LM35. Dengan menggunakan formula rangkaian pembagi tegangan dan $\mathrm{Vi}$ sama dengan Vin maka diperoleh:

$$
A v=1+\frac{R f}{R 2}
$$

Dengan demikian penguat operasi dengan konfigurasi ini penguatan tegangan Av akan lebih besar dari 1, ini berbeda dengan konfigurasi penguat operasi membalik.

\section{$\underline{\mathrm{ADC} 0804}$}

ADC (Analog to Digital Converter) adalah sebuah piranti yang dirancang untuk menubah sinyal analog menjadi sinyal-sinyal digital. Data analog yang keluar dai IC-LM35 yang ditambah penguat Op-Amp LM-358 akan diolah di data ADC 0804 dan keluar sebagai data digital 8 bit dengan nilai maksimal 255 atau setara dengan 1111 11112. ADC juga memerlukan detak atau clock untuk mengkonversikan sinyal analog menjadi data digital sebanyak 8 bit, konversi detak harus terletak dalam daerah frekuensi 100 sampai $800 \mathrm{kHz}$ pada pin 4 (CLK IN). Pada A/D ini sudah terdapat pembangkit clock internal dengan memasang rangkaian $\mathrm{RC}$ antara pin 4 (CLK IN) dan pin 19 (CLK R). Pin 5 adalah saluran yang digunakan untuk INTR, sinyal selesai konversi. INTR akan menjadi tinggi pada saat memulai konversi, dan akan aktif rendah bila konversi telah selesai. Sedangkan pin 20 merupakan pin dimana pin untuk pemberian tegangan atau cata daya ke rangkaian A/D dimana tegangan kerja yang dibutuhkan sebesar tegangan sekitar $5 \mathrm{~V}$ DC.

\section{Antar-muka}

Setelah terkonversi dari data analog berupa suhu menjadi data digital berupa tegangan yang dibuat sebanyak 8 bit akan diteruskan kedalam tampilan komputer / laptop. Sensor yang penulis bangun aadalah menggunakan port paralel, sehingga hanya dapat digunakan bagi komputer / laptop yang memiliki port paralel. Port paralel adalah sebuah port 8 bit yang umumnya dikenal juga sebagai port printer dengan memiliki port paralel dengan 25 jalur (DB25) dan Centronics (36 pin). Port paralel ialah port 8 bit yang dapat mengirim atau menerima data serentak sebesar 8 
data. Untuk membuat program kendali sensor agar dapat masuk ke PC / laptop , penulis menggunakan Visual Basic.

\section{$\underline{\text { Tampilan Komputer }}$}

Setelah diolah sedemikian rupa dengan menggunakan Visual Basic, program yang berisi tampilan informasi suhu dengan memberikan nilai suhu dan indikator sebagai pertimbangan perawatan komputer. Berikut tampilan program pembacaan suhu komputer;

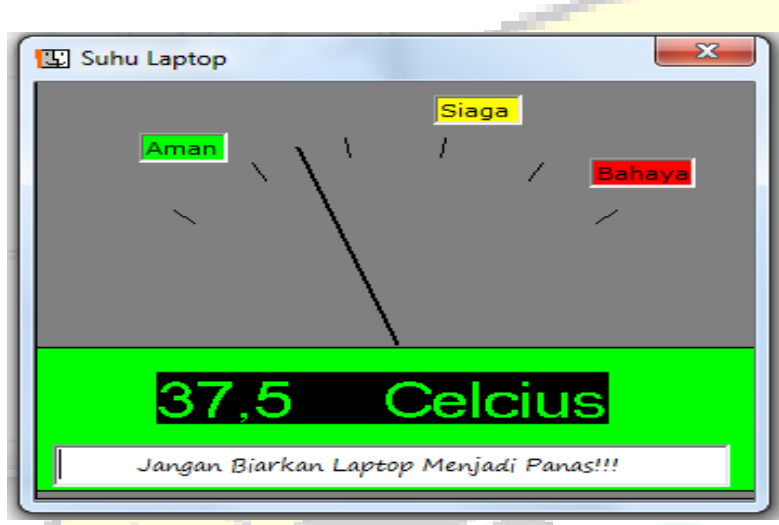

Gambar 4 : Tampilan Program Monitoring Suhu Komputer

Indikator yang penulis sediakan disediakan meliputi monitoring keseluruhan fisik mesin dan komponen komputer. :

1. Aman; suhu normal komputer aktif secara keseluruhan, yaitu $40^{\circ} \mathrm{C}$ hingga $60^{\circ} \mathrm{C}$. Maka dari itu menurut penulis, suhu aman komputer adalah dibawah $50^{\circ} \mathrm{C}$.

2. Siaga; suhu overheat adalah lebih dari $75^{\circ} \mathrm{C}$, sehingga bila komputer mengalami suhu $60^{\circ} \mathrm{C}$ hingga $70^{\circ} \mathrm{C}$ maka komputer harus siaga. Sebagai wujud perawatan, maka bila komputer mencapai rentang siaga sebaiknya komputer bisa di istirahatkan.

3. Bahaya; penunjukan suhu overheat yakni diatas $75^{\circ} \mathrm{C}$ akan sangat berbahaya bagi kondisi komputer tersebut.bila terjadi kondisiini, maka wajib komputer untuk disitirahatkan.

\section{HASIL DAN PEMBAHASAN}

Berikut adalah tampilan dari perangkat sensor suhu dan monitoring yang sedang di uji coba :

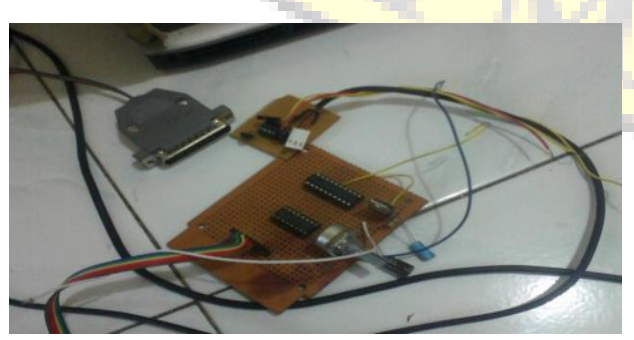

Gambar 5 : Perangkat sensor suhu monitoring komputer

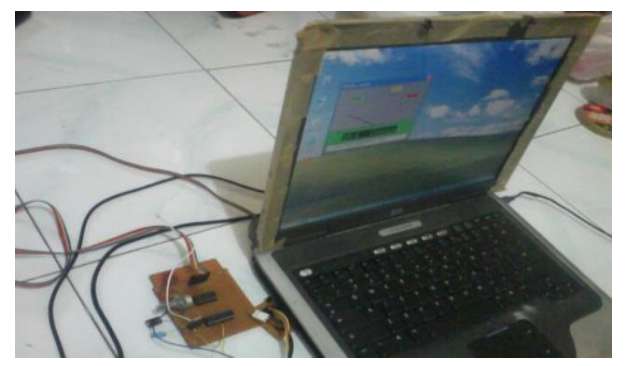

Gambar 6 : Uji coba perangkat sensor monitoring suhu

Uji-coba dilakukan ke sebuah laptop yang memiliki port paralel. Sensor diletakan pada badan laptop. Laptop tersebut sengaja dipakai selama beberapa jam untuk dideteksi suhu dan kerja monitoringnya. Selama uji-coba, suhu bekerja dengan baik mengukur suhu hingga $60^{\circ} \mathrm{C}$. Bila laptop terus dibiarkan bekerja dalam kondisi panas, maka suhu akan menunjukan suhu lebih dari $60^{\circ} \mathrm{C}$ menunjukan bahwa laptop perlu diisirahatkan.

\section{PENUTUP}

Setelah dilakukan pembuatan sensor suhu sebagai monitoring suhu komputer / laptop, dapat disimpulkan :

1. Sensor Suhu dibangun dengan memanfaatkan IC LM35 dan bekerja dengan baik mengukur suhu laptop.

2. Sensor ini menggunakan ADC-0804 dan port paralel yang menggunakan Pemrograman Visual Basic yang dapat memonitoring suhu komputer dengan baik lansung pada komputer tersebut.

3. Sensor dan monitoring komputer ini adalah sebagai salah satu cara perawatan dengan mengetahui tingkat suhu pada saat penggunaan.

\section{DAFTAR PUSTAKA}

[1] Intel, 2013, "Intel Core i7-4765T Processor (8M Cache, up to $3.00 \mathrm{GHz})$ ", http://ark.intel.com/ products/75121/Intel-Core-i7-4765T-Processor-8MCache-up-to-3_00-GHz, 2014

[2] Pusat Data dan Sarana Informatika Kementrian Komunikasi dan Informatika, "Hasil Survei penggunaan Teknologi Informasi dan Komunikasi (TIK) di Sektor Bisnis Indonesia 2011”, ISBN 978602-98285-3-5, 2011

[3] Budiharto, W. "12 Proyek Sistem Akusisi Data". Elex Media Komputindo. Jakarta Syafitri, A. D. 2011. "Penerapan Sensor Suhu IC LM35 Pada Termometer Ruang". http://www.slideshare.net/ myauwnaanggun/sensor-suhu-lm35. 2007

[4] Banu. "Periksa Temperatur Laptop/PC Anda" http://banuaw.wordpress.com/2011/02/13/periksatemperature-laptoppc-anda/ . 2013 